\title{
The Design of New Media Art: Combination of Art and Digital Technologies
}

\author{
Liping LIU \\ Henan Economy and Trade Vocational College \\ Zhengzhou,Henan,450018 China
}

\begin{abstract}
Modern society has entered the digital age, and human civilization has made unprecedented progress. As a kind of new art form, the design of new media art development with it. Art and design are influenced by digital technology deeply. There are many disadvantages but already occupies a very important position in art and design industry. How to resolve the fine tradition, holding and innovating, training personnel is being the key to get the development in the design of new media art.
\end{abstract}

Keywords- Art; Digital Technology; The Design of New Media Art

\section{MAINTAIN THE FINE TRADITION IN THE DESIGN OF NEW MEDIA ART}

The design of new media art is the same as the new art form of human society that are inherited and developed on the traditional elements, which is developed basic in the fine tradition. The works not only ensure the functionality, but also maintain the beauty. Various theory criterion and traditional art and design are similar to its best. It's just different from traditional forms of artistic, which shows technical like light, electricity and other modern technology. From here we see that the design of new media art just enrich and innovate the forms of traditional artistic designs and maintain the fine tradition. New forms enrich people's vision greatly, and the development of various forms of information makes the limitations of traditional art and design. Due to the rapidly develop of modern science and technology, digital art and design has shown weakness in design and aesthetic theory, traditional art and design theory will continue as the foundation to the design of new media art.

\section{THE RISE OF THE DESIGN OF NEW MEDIA ART}

Every great advance in science will have a huge impact in the field of art and design, meanwhile it becomes the force of development and prosperity in art form. In the development of the whole art, we can see that the study of medicine and human anatomy for drawing, sculpture creation theory provides an important reference; geometric perspective learning and development, in order to provide a perspective drawing theory in line with the principle of human vision ; pigment chemistry progress, painting home offers bright and rich color gradation performance space; further development of optics research, so follow the principles of optics impressionist painter, analysis and organization of images of the various relationships, but also research for optical applications led to the birth of photography, art and thus had a profound impact, which embodies everything important role in promoting science and technology for the arts.

Since the turn of 20th century, the impact of technology on the arts become more intense and rapid, the development of digital technology provide more broad art creation performance space. In the early 1980s, computer graphic art design has become the means and forms of contemporary visual representation tip, rapidly appeared in the fields of mess media and visual artists like television, film, graphic art design, industrial design, display art and design and the built environment art design and so on. The emergence of computer graphics is called the third graphic revolution, and its significance is even greater than the first two images revolution that from silent to sound, from black and white to color.... From the 1990s to now, "Digital Art Design" appears in an entirely new way in art and design field, it combines two completely different disciplines--"art" and "Computer Science and Technology". Digital Media Arts is an art form based on the rapidly development of the nascent digital technology produced on the characteristics of new media art, new media art pioneer Roy Ascot said:" the new media art's most distinctive trait is connectivity and interactivity". From the international academic and educational set to digitalize "design" many other titles and the scientific content to see, digital media arts mainly related to the visual arts, human-machine interface, information dissemination, multimedia, the basic connotation of digital networks, animation, advertising, games, virtual environments, virtual product design and so on. Digital Media Art and Design is the art of traditional design and rich stretch the emergence of new forms of communication and the media, so that get rich and expand greatly in the contents of visual communication art and design. Networks, digital television, interactive media, interactive games, virtual space and so on become the main media forms and information dissemination, the traditional groundbreaking visual communication design category by the impact of the development of digital carriers greatly extended form visual communication and design content, under the rapidly 
development of contemporary digital art and design, design theory and aesthetic theory of digital media art are very weak.

\section{THE DEVELOPMENT FEATURE OF THE DESIGN OF NEW MEDIA ART}

The development of new media art and design stage has become an emerging art form lead by technology currently. We understand and create art before are derived from the formation of our own culture and subjective aesthetic ideology, which has been existed the basic painting, music, sculpture and decorative art forms. With their pursuit of ever-changing concept, people's awareness has played a primitive and guided role in traditional art. Today's media, art and design are birth for our consciousness, the existence of such a product, not only let us pay attention to the importance between art and new media, but also pay attention to the use of new media technology, it will be able to find more good development in innovation and extension.

It would appear from the above that as people pursue their own evolving concept, and their awareness has become a primitive and guided role in traditional art. In this case, we need to study this kind of demand. Its expression is diverse and widespread popular and scientific era of information, at this stage the data and the commercial properties are the main features. Therefore, in the design of new media art, we must introduce new methods, fashionable, innovative development, and combine the media and the arts together to improve the research of emerging technologies.

New media art expression better in visual design. Along with the constantly update in current technology, the new technology will continually spawned out. With new forms of communication, there will be the emerging new media art and design works, so there are network media, Interactive media and games, virtual space and the generation and development of digital television, thereby forming a good platform for the display. So opposed to the traditional visual communication, its visual communication design category has a great impact, thus better rich and extensible the design in the form and content of the visual system.

\section{THE PRACTICE OF NEW MEDIA ART}

When we are faced with specific phenomenon in new media art, we will often find that there is a rarely phenomenon full of that definition, but a lot of are in one respect or the extent consistent with the definition not so "pure" in new media art. For example: the use of a number of technical means of new media, but overall still belong to the traditional works of art; completely relying on digital technology, but it is not pure art; traditional artwork copied in digitally and so on. We are not get rid of them all, the vision that will enable us to become extremely narrow; nor bring into all phenomenon without analysis in the study areas of new media art, that will make the new media art concept becomes vague, it is not conducive to reveal the basic features of the new media art.

New media art is accompanied by new media technologies evolved from traditional art, so its quality and performance in their own traditional art forms and is nature in inextricably linked; new media art has a strong vitality and expressive, so its also very nature spread by people for nonart information. We need to recognize such inextricably linked between the new media arts and traditional arts, and must reveal the special nature of new media art which different from the traditional arts; we have to face the new media art's artistic expression is widely used in non-art information dissemination of reality, and can not blur the boundaries of art and non-art. The correct approach is to scientifically analyze the complex structure of the new media art object of study, accurate positioning of the various elements and be treated differently.

\section{ANALYZING PROBLEMS OF DEVELOPMENT IN THE DESIGN OF NEW MEDIA ART}

Integration of different disciplinary research methods is important especially in the integration of technology research and artistic perspective study. New media art itself is rapidly developing art form with a powerful platform in new media technologies, as researchers, we must examine the phenomenon always from a theoretical perspective that in deep interactive science and technology literature and art. This review relies for the pursuit of the perfect unity of human beings matter and spirit, reason and emotion, knowledge and experience, a deep understanding of ideological history. The key is the inherent "integration", rather than external "adding", the purpose of the new media art phenomenon is real restored in multiple causes and multiple property. Humanities and social sciences research methods inside the various disciplines should also be absorbed integration, such as it is essential for cultural and social psychology, communication studies methods for reference. To achieve the integration of research groups, the establishment of interdisciplinary arts complex research groups. Since the creation and study of new media art started late in China, there is a rarely researchers in the long-term participation in the new media, which can maintain theoretical thinking on their own artistic practice and others are even fewer. That makes the more profound practical and theoretical researchers accumulation became scarce resources, which restricts the depth of new media art research. The New Media Art Institute is needed the typical compound talents, not only professional knowledge and skills should be mastered more than two art, to have more profound knowledge of cultural history subjects, but also familiar with multimedia computer network technology and related application software. However, the existing model of professional art research division, not only split liberal arts and science, split liberal arts and science and art, also split various categories of art, such a system is not in favor of new media arts complex talent to grow.

From the 1980's to present, under the impetus of scientific and technological strength, China's new media art and design has been rapidly development, whether it's visual style, or design concepts are becoming more mature. However, compared to the status quo and development of new media art and design of the West, China is still a series of problems in urgent, in general, these problems are mainly reflected in the following aspects: 
Artists lack of sufficient artistic ideas. In a market economy, digital technology is rapidly development in the wave of business together, and its greatest feature is the practicality in order to meet people's needs and aesthetic preferences. The new media art and design as a product of digital technology are bound with a strong commercial color, the work starting point with a strong utilitarian purpose. Therefore, designers often lack reflections on artistry, not to say non-commercial emerging digital art design work, which is totally incompatible with the non-utilitarian artistic disciplines law of development. Thus, properly understood, it is essential to understand and explore the law of development of digital technologies in new media art design.

The artists are lack of importance of new media art and design artists. In reality, the process of artistic creation, many artists still holding the traditional design thinking and design, light, electricity, things like instrument cherished sense of exclusion, or the feeling of these high-tech, post-modern art seems from their very away, or that this lack of utilitarian behavior is called art, and therefore, there is disdain worth for the effort. However, a well-known new media art designer van Dean believes: first combination of art and technology may not produce practical products, but it does have great potential for the application of the conversion, and indicates that the future of life, artistic creativity, innovation always inspire people to create new understanding.

Digital art is an interdisciplinary and multidisciplinary complex combination of discipline, cultivating and training not only understand the laws of art and design, but also know how computer graphic art design, digital art and design talent capable of operating-related applications and post-production software, has become today's digital art and design industry imminent need to address the issue. Digital technology talent and creative talent are social need, but there is a huge demand for the proportion of the difference, according to market demand and therefore need to develop the culture of different levels of technical personnel and creative talent educational goals.

Finally, the problem is to develop an object. With the popularity of the development of education, more and more students into the arts disciplines, the attendant gave rise to conflicting problem students overall quality and artistic expertise, their comprehensive training and knowledge structure is widespread dislocation the problem, which the new media professional teaching and training has brought great difficulties, this phenomenon in art schools was particularly prominent, we can consider digital media arts education should not be limited to art students.

\section{CONCLUSIONS}

In the multimedia art design, our technology base can be said to be pulled in the same starting line, in other words any ideas (including those who lack the creative and stupid) can handle very dizzy and professional, so good design ideas are more precious. From the dialectical relationship between science and art, we can know that while high-tech design tools must be brought demand for high emotion. Multimedia art and design along contemporary technological developments from homeopathy, also corresponds to the human complex and diverse high emotional needs emerged. There is no doubt that the source of life or creation and creative thinking are still the core of multimedia art and design. The difference is that we created works and feelings have been integrated into our lives and became part of our life. The new digital media and art is a new media form, compared with the television media, broadcast media, update and disseminate faster, more interactive, people through new media for more information. In the new media art and design, first need to enhance the understanding of new media art and design, to improve the degree of attention, the design should follow the theoretical basis of the aesthetic, visual and creative theoretical laws, etc., so that it can content the basic requirements of functionality. Art institutions should also strive to train new media art and design development of professional personnel, and jointly promote the development of new media.

\section{REFERENCES}

[1] Sang Lijun. The study of the design of new media art in combined with art and digital technology [J] writers, 2013,24: 301-302.

[2] Ren Bin. The design of new media art in combined with art and digital technology [J] Northwest University (Philosophy and Social Sciences), 2008,06: 191-193.

[3] Zheng Fei. My oppinon in the design of new media art in combined with art and digital technology [J] art technology, 2013,02: 19.

[4] Pang Xiaoying. The design of new media art in combined with art and digital technology [J] art technology, 2013,12: 93.

[5] Yang Zhigui. About the design of new media art in combined with art and digital technology $[\mathrm{J}]$ Chinese new technologies and products, 2011,13: 229-230.

[6] Lin Si. Analysis of the design of new media art in combined with art and digital technology $[\mathrm{J}]$ modern decor (theory), 2013,12: 101.

[7] Li Peng. Analysis of he design of new media art in combined with art and media technology [A] China Proceedings Creative Design Yearbook 2013 [C]:, 2014: 3. 